\title{
TEORIA DO DIREITO NA PÓS-MODERNIDADE: REFLEXÕES A PARTIR DA SUSTENTABILIDADE À SENSIBILIDADE
}

\section{THE THEORY OF LAW IN POST-MODERNITY: REFLECTION FROM SUSTAINABILITY TO SENSITIVITY}

${ }^{1}$ Suzete Habitzreuter Hartke

\begin{abstract}
RESUMO
O Direito representa expressão da Cultura humana. Diante desse contexto, o artigo tem como objetivo apresentar propostas de possíveis soluções a um problema que muito se faz presente na Pós-modernidade, qual seja: o Direito que está sendo produzido hoje parece não resolver os problemas relacionados ao Desenvolvimento Sustentável e que são submetidos ao Judiciário brasileiro, com base no Método Indutivo. A solução está na utilização da Razão Sensível e da Política Jurídica, por permitirem que se corrija o Direito vigente e a construção daquele que pode vir a ter em sentido humanitário.
\end{abstract}

Palavras-chave: Teoria do direito, Segurança jurídica, Ativismo judicial, Política jurídica, Sustentabilidade

\begin{abstract}
The Law represents one expression of the human Culture. Facing such context, this paper aims at presenting proposals of possible solutions to a problem that is present in postmodernity, which is: the Law produced nowadays does not seem to solve the problems related to Sustainable development which are submitted to the Brazilian Legal System, the methodology used the Inductive Method. The solution resides in the use of Sensitive Reasoning and the Law Politics, since they enable the correction of the current law and the construction of the one that might exist in a humanitarian sense.
\end{abstract}

Keywords: Theory of law, Law safety, Judicial activism, Law politics, Sustainability

\footnotetext{
${ }^{1}$ Mestre em Ciência Jurídica pela Universidade do Vale do Itajaí - UNIVALI, Santa Catarina (Brasil). Professora pela Instituto Blumenauense de Ensino Superior - IBES, Santa Catarina (Brasil).

E-mail: suzetehh@gmail.com
} 


\section{INTRODUÇÃO}

Neste estudo procura-se apresentar propostas de possíveis soluções a um problema que muito se faz presente na Pós-modernidade ${ }^{1}$, qual seja: o Direito que está sendo produzido hoje parece não resolver os problemas relacionados ao Desenvolvimento Sustentável e que são submetidos ao Judiciário brasileiro. Apesar de o jurisdicionado obter uma decisão judicial, os problemas relacionados e/ou decorrentes do Desenvolvimento Sustentável não se resolvem de forma satisfatória, efetiva e real. Diante dessa constatação empírica, pretende-se, a partir de uma reflexão crítica de filósofos e teóricos ${ }^{2}$ como Platão, Reale, Maffesoli, Streck e Melo, apresentar uma solução ao problema.

A partir deste problema, entende-se que uma das soluções possíveis seria a adoção da Política Jurídica e não do Ativismo Judicial, como forma de solucionar a questão. A Política Jurídica permite a adoção da Razão Sensível aos conflitos envolvendo os Seres humanos ${ }^{3}$ na Pós-modernidade. Entende-se como necessário abandonar a primazia da Razão lógica e adotar um novo paradigma.

A pesquisa reflexiva a partir da leitura de Platão, Reale, Maffesoli, Streck e Melo, serve de ponto de partida para identificar esse novo modelo que possibilitará o

1 Para construção do conceito operacional dessa categoria, a Autora apropria-se das dimensões de Pósmodernidade teorizadas pelos autores consultados: Os valdo Ferreira de Melo e Jean Lyotar que descrevem o que vem a ser esse momento vivido pela Sociedade atual batizada precariamente nos meios acadêmicos de Pós moderno ou Pós-modernidade. De acordo com Melo “[...] estamos vivendo um período de transição, o que s ignifica a ruptura dos paradigmas da modernidade e a passagem para uma fase subseqüente que, à falta do batismo que só deverá ocorrer num futuro imprecis o, chamaremos precariamente de pós -modernidade, para usar de expressão genérica já corrente nos meios acadêmicos. MELO, Osvaldo Ferreira de. Fundamentos da política jurídica. Porto Alegre: Sérgio Antonio Fabris Editor/CPGC-UFSC. 1994. p. 18. Para Lyotar: “[...] A palavra é usada, no continente americano, por sociólogos e críticos. Designa o estado da cultura após as transformações que afetaram as regras dos jogos da ciência, da literatura e das artes a partir do final do século XIX.”. (LYOTARD, 2006, p. XV).

2 Segundo as lições de Motta da Silva, o autor e o leitor devem ter clareza que há diferença entre a categoria Doutrina e Teoria. Para Motta da Silva "Doutrina: Expõe a ideia do autor fundada no direito positivo e a partir dis so ele emite um juízo de valor sobre a matéria enfocada. É o pensamento dele sobre o tema que está focalizando, sem análise reflexiva. A doutrina perde a caracterís tica de cientificidade, pois se baseia apenas no direito positivo, mediante um juízo de valor. A doutrina tem caráter de ensinamento. Teoria: A teoria opera com fundamentos metodológicos e de conteúdo sempre de caráter reflexivo. A teoria precis a determinar o seu objeto; após segue-se a indicação dos objetivos da teoria; há também a previsão de hipóteses, a referência a possíveis variáveis. Há indicação de que os resultados obtidos são de caráter provisório, portanto sujeitos a uma nova reformulação. Toda teoria, por envolver uma investigação científica, terá o conceito de verdade sempre como provisório. O principal pressuposto de uma teoria está na linguagem. Esta requer excelência na s ua aplicação. Significa, essa observação de que a linguagem empregada na teoria filosófica se opera com o emprego de "categorias" - palavras ou expressões de sentido específico." Informação verbal, conforme as palavras de Moacyr Motta da Silva, em aula ministrada no curso de Mestrado em Ciência Jurídica da Univali, dia 22 ago. 2005, na disciplina de Teorias da Justiça e da Juris dição.

3 Para lógica deste estudo, adere-se ao conceito operacional proposto para "Ser humano" formulado por Nedel, como sendo aquele Ser dotado de "[...] privilégio de singularidade absoluta entre todos os viventes naturais". (NEDEL, 2004. p. 238). 
desenvolvimento de uma Teoria do Direito na Pós-modernidade ${ }^{4}$, à luz da Filosofia do Direito, a qual poderá dar respostas "melhores" a questões que envolvam as demandas sociais, coletivas e/ou individuais de Seres humanos atreladas ao Desenvolvimento Sustentável.

O critério metodológico utilizado para a investigação deste estudo e a base lógica do relato dos resultados apresentados reside no Método Indutivo. Para o desenvolvimento da pesquisa, o percurso teórico acha-se distribuído em dez tópicos. No primeiro, apresentam-se os fundamentos do Direito para na continuidade serem apresentados alguns fundamentos da Razão, da Sensibilidade, da Sustentabilidade, do Princípio da Segurança Jurídica, do Ativismo Judicial, da Política Jurídica e, em seguida, as Considerações finais.

\section{FUNDAMENTOS DO DIREITO}

A categoria Direito comporta ser estudada em vários sentidos: Cultural, Social, Político e Jurídico. Em razão disso se faz necessário estabelecer um acordo semântico quanto ao sentido da referida categoria. Neste estudo adota-se a ideia do Direito, a partir de uma perspectiva multidisciplinar. (PASSOLD, 2011).

A ideia do Direito como norma, ou fato, ou valor é um equívoco conforme destaca Reale (2002). O Direito deve ser entendido "à luz da experiência social e histórica do homem" (REALE, 2002, p. 700). Na busca de nova forma de construí-lo, Reale (2005) formula a Teoria Tridimensional do Direito. Essa teoria tem por escopo possibilitar uma visão integral do Direito. É caracterizada pela correlação dialética de Fato, Valor e Norma. É um novo paradigma do Direito. Até então ele era entendido de forma isolada. Ora como Fato, ora como Valor, ora como Norma.

Entende-se o Direito como construção do Ser humano (REALE, 2005), em sua vivência em Sociedade5. Por isso é adequada a afirmação de Longo (2004) que diz: "o Direito

\footnotetext{
4 A categoria Pós-modernidade é utilizada sob o ângulo da Filosofia do Direito. A dimensão da expressão que adotamos para lógica deste estudo, segundo Moacyr Motta da Silva, propõe-se a analisar o esgotamento do Positivismo Jurídico dogmático no terceiro milênio. Esse tempo, denominado Pós -modernidade, tem caráter interdisciplinar. Busca o sentido da Norma Jurídica a partir da Ética, da Jus tiça, da Moral que alicerçadas na tolerância, na boa vontade, no reconhecimento da desigualdade, na justiça e na paz produzem práticas sociais desejáveis de um futuro porvir. (SILVA, 2009).

5 Para a lógica deste trabalho a categoria Sociedade será utilizada no sentido de ser a reunião plural de Seres humanos. É um fenômeno Cultural e Histórico. Esse conceito foi elaborado a partir de Miguel Reale, para quem a Sociedade "[...] é, em suma, também realidade cultural e não mero fato natural. A sociedade das abelhas e dos cas tores pode ser vista como um simples dado da natureza, porquanto es ses animais vivem hoje, como viveram no passado e hão de viver no futuro. A convivência dos homens, ao contrário, é algo que se modifica através do tempo, sofrendo influências várias, alterando-s e de lugar para lugar e de época para época." REALE, Miguel. Lições preliminares de direito. 13. ed. São Paulo: Saraiva, 1986. 381 p. E também, de acordo com Motta da Silva que afirma ser "a Sociedade humana um fenômeno histórico. Ela vem crescendo e se transformando". Conforme s uas palavras proferidas em aula ministrada no curso de Mestrado em Ciência Jurídica da Univali, dia 19 abr. 2006, na disciplina de Novos Direitos: entre o Público e o Privado.
} 
não é só uma construção do homem, mas é o próprio homem. Não é, simplesmente, um objeto criado por um sujeito, mas é o sujeito e o seu próprio objeto".

Para Reale (2002, p. 699-713) o Direito não pode ser visto apenas como "pura norma". Constitui um bem cultural ${ }^{6}$. No mesmo sentido é a posição de Osvaldo Ferreira de Melo, para quem o Direito também é um fenômeno cultural (MELO, 1998, P. 85), construído historicamente pela experiência na vida social e nas práticas comunitárias (MELO, 2014).

O Direito como expressão normativa da Sociedade nasce como síntese da Cultura. É a Sociedade, por sua vontade, seus interesses morais, éticos, econômicos e políticos, a criadora do Direito. O Direito representa expressão da Cultura humana. Vai além dos códigos e das leis. Parafraseando Reale 7 , o Direito é a união do "ser" e do "dever ser". Representa uma ciência social e humana ${ }^{8}$.

O Direito, assim compreendido, revela uma Utopia9 . "Não é um projeto irrealizável para o ser humano, ou até pode sê-lo, neste espaço e neste tempo, mas não por todo o tempo e em todo lugar" (LONGO, 2004, p. 118). Pode-se dizer que o Direito é emanação do Ser humano ${ }^{10}$.

\footnotetext{
${ }^{6}$ Por Cultura, Miguel Reale entende: "[...] "cultura" é o conjunto de tudo aquilo que, nos planos materiais e espirituais, o homem constrói sobre a base da natureza, quer para modificá -la, quer para modificar-se a si mesmo. É desse modo, o conjunto dos utensílios e instrumentos, das obras e serviços, assim como das atitudes espirituais e formas de comportamento que o homem veio formando e aperfeiçoando, através da história, como cabedal ou patrimônio da espécie humana". (REALE, 1986, p. 25-26).

7 "O direito é, pois, uma espécie de experiência cultural, isto é, uma realidade que resulta da natureza social e histórica do homem, o que exige nele se considere, concomitantemente, tanto o que é natural como o que é construído, as contribuições criadoras, que consciente e voluntariamente se int egram e continuam se integrando nos sistemas jurídicos-políticos. Daí se apresentar sempre como síntese ou integração de "ser" e de "dever ser", de fatos e valores, quer em experiências particulares, quer na experiência global dos ordenamentos objetivados na história”. (REALE, 1992. p. 111-112. Sem grifo no original).

8 Essa afirmativa foi construída a partir da reflexão crítica da obra de (LONGO, 2004, p.262), em especial nas páginas 3 e 45. O autor diz que o Direito é uma ciência social [p. 3] e uma ciência humana [p. 45]. De acordo com Aurélio, "Ciências sociais são aquelas cujo objeto de estudo são os diferentes aspectos das sociedades humanas. E Ciências humanas são aquelas que estudam o comportamento do homem individual ou coletivamente, como, entre outras, a psicologia, a filosofia, a lingüística e a história". (FERREIRA, 1986. p. 404). Verbete Ciência. Para Longo o Direito não é só algo exterior ao Ser humano. Ele também integra o interior desse Ser humano. Tanto que o "Direito é o Homem e o Homem é o Direito". Verifica-se nesse caso que há relação do Ser humano em Sociedade (objeto das Ciências sociais), como também do Ser humano enquanto Ser (objeto das Ciências humanas).

9 "UTOPIA - No sentido filosófico, uma ideologia posta em ação, com vistas ao alcance da situação melhor possível. (MELO, 2000, p. 96). Verbete Utopia.

10 "O Direito é um objeto do homem porque existe por ele e para ele. Ou, em um sentido profundo, sob o aspecto universal, o Direito é o Homem. Então, o sujeito-Homem e o objeto-Direito se fundem como origem e finalidade de um mesmo ser, maior do que ambos, gênero que fundamente essas duas espécies, e que é a Vida". (p. 13) "[...] homem é um ser-sujeito que existe para viver o Direito; e o Direito é um ser-objeto que vive para existir no homem". (p. 15). Ambas as citações extraídas da obra (LONGO, 2004).
} 


\section{FUNDAMENTOS DA RAZÃO}

A ideia de Razão, para este estudo, parte do trabalho de Motta da Silva (2010). De acordo com a filosofia de Kant (Apud SILVA, 2010, p. 91-116), o autor utiliza o termo Razão, acrescido de qualificativos como: razão vulgar, razão pura, razão pura prática, razão comum. Diante dos vários qualificativos e modelos de Razão utilizados por Motta da Silva, este reconhece que a Razão é inerente ao Ser humano e tem por sede a sua alma ${ }^{11}$.

Como se pode depreender da filosofia de Kant, a Razão também está ligada umbilicalmente ao Ser humano. Segue a mesma linha que o Direito. Todavia, para Kant o Direito é fruto da Razão humana. Não se deduz da experiência. É a Razão que explica o Direito.

Ao definir e descrever dois tipos de Razão, a Razão de $\operatorname{Ser}^{12}$ [ratio essendi] e a Razão de Conhecer ${ }^{13}$ [ratio cognoscendi], Kant parece reconhecer que a Razão não pode ser entendida apenas como o conhecimento puro, desprovido de emoção e sentimento. Ela apresenta-se no Ser humano com duas faces.

A ideia da Razão como fonte mais elevada do conhecimento humano é identificada na história da humanidade como "Racionalismo"14. O Racionalismo não admite, de forma exclusiva, a construção do conhecimento humano a partir do mundo dos fatos, ou da experiência ${ }^{15}$. Admite, somente de forma acessória, o mundo dos fatos. Os fatos apenas auxiliam a construção do conhecimento, de forma intuitiva ${ }^{16}$.

\footnotetext{
${ }^{11}$ A alma humana é empregada no sentido de intelecto. (SILVA, 2010, p.99).

12 "A ratio essendi ou razão de ser refere-se ao conhecimento empírico, vinculado à realidade sensível". (SILVA, 2010, p. 99).

13 "A ratio cognoscendi ou razão de conhecer compreende o conhecimento puro, fundado na razão pura, especulativa." (SILVA, 2010, p. 99).

14 De acordo com Moacyr Motta da Silva, o "Racionalis mo surgiu Entre os séculos XVII e XVIII floresceu na Europa continental, particularmente na França, linha de pensamento voltada ao estudo do conhecimento humano, centrada na razão, como fundamento de todas as coisas. Esse movimento expandiu-se, notadamente às investigações no âmbito da Ética, da moral, do direito, da política, da religião. Racionalis mo designa, em sentido amplo, a linha de pensamento filosófico que prioriza a razão, sobre a experiência, como fonte do conhecimento." (SILVA, 2010, p. 646).

15 O mundo dos fatos, ou da experiência, é identifica do na história da humanidade como Empirismo. O Empiris mo parece ter surgido na Inglaterra e é descrito por Moacyr Motta da Silva como: "Empiris mo, em s entido amplo, designa as correntes doutrinárias que não aceitam axiomas, verdades absolutas, como princíp ios relativos ao conhecimento. O Empirismo apoia-se na experiência, porém o grau de validade dos enunciados funda-se no exame dos fatos, metodicamente pesquisados e demonstrados. Predomina, no Empiris mo, a verdade lógica na construção dos enunciados ." (SILVA, 2010, p. 179). Nota de rodapé n. 646.

16 Para a lógica desse estudo, adota-se o conceito operacional de intuição formulado por Motta da Silva: "Entende-s e por intuição [...] o conhecimento imediato, que se apreende do objeto. Em princípio, a intuição opera-se ora por meio dos sentidos, por exemplo: percepção do calor; da forma dos objetos; da distinção das cores; ora por meio intelectual, do tipo: aquele em que o ser se esforça por apreender diretamente a essência do objeto, construindo ideia do objeto. A intuição nasce do espírito reflexivo do ser; independe de inferência intelectiva complexa; resulta de processo de abstração mental; desenvolve -se espontaneamente, mediante operação mental, direta com o objeto." (SILVA, 2010, p. 180).
} 
Agostinho (Apud CASSIRER, 2005, p. 22-23) rompe com o pensamento que havia no Século IV. Nesse momento histórico, a Razão era considerada a fonte maior do conhecimento humano. Ele declara, segundo descreve Cassirer, que a Razão é obscura ${ }^{17}$. Após a "queda"18 do Ser humano, esse não é mais imagem e semelhança de seu Criador"19. E assim, a Razão como algo inerente ao Ser humano não pode mais ser considerada como o mais alto poder do Ser humano, pois esse Ser humano é pecador ${ }^{20}$. Agostinho arremata a discussão quanto o domínio absoluto da Razão de forma decisiva. Afirma que ela é limitada e finita ${ }^{21}$.

O Ser humano pela Razão e não por revelação divina ou fruto do mundo natural, com base no Conhecimento - decorrente da Razão -, estará apto a produzir e aplicar o Direito que desejar, por ser o único Ser pensante capaz de intervir no mundo da Cultura.

\section{FUNDAMENTOS DA SENSIBILIDADE}

Sensibilidade constitui uma categoria polissêmica. Neste estudo será utilizada como a capacidade do Ser humano em compartilhar as emoções alheias ou de simpatizar com elas ${ }^{22}$.

A Sensibilidade vem sendo abordada por filósofos (BOFF, 2000; DUSSEL, 2002; MAFFESOLI, 1998) contemporâneos como integrante do conhecimento humano. Neste trabalho, privilegiam-se as ideias de Michel Maffesoli.

\footnotetext{
17 "Alguns descobriram grandes verdades, enquanto Deus lhes prestou auxílio, mas, enquanto escravos da fraqueza humana, caíram no erro; a Providência divina resistiu-lhes justamente ao orgulho, para mostrar, com o próprio exemplo desses homens, o caminho da piedade que do fund o da humildade se eleva ao céu, questão que com a graça do verdadeiro Deus e Senhor teremos oportunidade de aprofundar e discutir." (AGOSTINHO, 2003. v. 2. Parte I, p. 75).

${ }^{18}$ A categoria queda é empregada no sentido de pecado. Do cometimento do "pecado original" que Adão e Eva efetuaram no paraíso. Situação descrita no livro de Gêneses, 3. (BÍBLIA SAGRADA. 2000. p. 4).

19 "Deus fez o homem à sua imagem e deu-lhe alma, dotada de razão e de inteligência, que o tornava superior a todos os restantes animais terrestres, nadadores e voadores, destituídos de mente". (AGOSTINHO, 2001. Parte II, p. 89).

${ }^{20}$ De acordo com Agostinho a fonte supre do saber só é encontrada em Deus e não no Ser humano: "Ora, assim como sois o Ser absoluto, assim também sois o único que possui a verdadeira ciência. In AGOSTINHO, Santo. Confissões. Tradução de J. Oliveira Santos e A. Ambrósio de Pina. 9. ed. Petrópolis : Vozes, 1988. p. 341. "O nome "filósofo", traduzido ao português, significaria "amor à sabedoria". Pois bem, se a sabedoria é Deus, por quem foram feitas todas as coisas, como demonstraram a autoridade divina e a verdade, o verdadeiro filós ofo é aquele que ama Deus”. AGOSTINHO, Santo. A cidade de Deus. 2003. Parte I. p. 341.

21 "A razão humana é limitada e finita. 1. Contudo, quando lhes falamos dos milagres de Deus, passados ou futuros, de que não podemos dar-lhes prova experimental, os infiéis pedem-nos o porquê deles. E, como não podemos dá-lo (pois excedem a capacidade da razão humana), julgam ser falso o que dizemos. Que nos dêem eles a razão de tantas maravilhas existentes ou sequer das de que podemos ser testemunhas!" (AGOSTINHO, 2001. Parte II, p. 489).

${ }^{22}$ De acordo com ilustração do Dicionário de Filosofia de Abbagnano, diz-se que é sensível quem se comove com os outros e insensível quem se mantém indiferente às emoções alheias. No presente estudo se privilegiará a s ensibilidade. (ABBAGNANO, 1998. p. 872). Verbete - Sensibilidade.
} 
Maffesoli (1998) parece condenar a característica essencial do racionalismo que "quer que tudo entre em uma categoria explicativa e totalizante.” Com a Razão, tudo é classificado. Mas imaginar que isso é possível, não passa de uma quimera. A realidade vivida pelo Ser humano não segue uma prévia classificação. Afinal, o Ser humano que vive é dotado de sentimentos e emoções e não só da Razão.

Há necessidade de afastar-se do olhar puramente racional e observar-se as aparências, as formas, todas as coisas sensíveis que integram a realidade humana ${ }^{23}$.

No momento de proferir a sentença judicial, entra em cena a Sensibilidade/formismo. Conjugam-se, então, as disposições da lei [Razão] com os fatos reais que integram o caso concreto [Sensibilidade/formismo].

Portanto, o Direito necessita ser entendido não só pela Razão, mas também pela Sensibilidade.

Constata-se que o ato de conjugar a Razão e a Sensibilidade não descaracteriza o ato judicial. Entende-se, assim, que a realidade da vida humana não se reduz à solução de seus problemas ou à aplicação de fórmulas ${ }^{24}$.

A vida empírica ${ }^{25}$, a experiência, está aí para demonstrar que a Razão deve caminhar ao lado da Sensibilidade, e que ela já ocupa um lugar inegável (MAFFESOLI, 1998). Afinal, como arremata Maffesoli (1998, p. 189), “o sensível não é mais um fator secundário na construção da realidade social".

\footnotetext{
${ }^{23}$ Essa forma de observar o real, fazendo uso da Sensibilidade, é denominada por Michel Maffes oli de Formis mo - "[...] prevalência da aparência, a necessidade de levar a sério todo o que os espíritos sérios consideram frívolo. Numa palavra, integrar à análise da vida social uma constatação bem trivial: o que é, é. Antes de extrair as conseqüências epistemológicas de uma tal constatação, pode-se, num primeiro momento, mostrar que a forma é de fato a matriz que gera todos os fenômenos estéticos que delimitam a cultura pós -moderna." (MAFFESOLI, 1998, p. 82).

${ }^{24}$ É com esse pensamento que Michel Maffesoli defende a utilização da Sensibilidade/Formis mo. Vejamos: "A fórmula tem respostas prontas, sobre tudo e sobre todos. Ao contrário, a forma, ou a sua expressão filosófica - o formis mo -, contenta-s e, em levantar problemas, fornecendo "condições de possibilidade" para responder a eles caso a caso e não de maneira abstrata.” (MAFFESOLI, 1998, p. 87).

25 "Empiris mo, em sentido amplo, designa as correntes doutrinárias que não aceitam axiomas, verdades absolutas, como princípios relativos ao conhecimento. O Empiris mo apoia-se na experiência, porém o grau de validade dos enunciados funda-se no exame dos fatos, metodicamente pesquisados e demonstrados. Predomina, no Empirismo, a verdade lógica na construção dos enunciados. Determinada corrente do Empiris mo teoriza que o conhecimento humano não tem sentido absoluto. Esta concepção entende que o homem jamais poderá alcançar o conhecimento, a verdade definitiva. O saber humano não consegue separar-se do mundo dos fatos, por maior es forço que haja no sentido de isolar o homem da realidade do mundo. Pensar as coisas do mundo fora do mes mo, constitui algo impossível, do ponto de vista da lógica. Neste particular, o conhecimento produzido pelo ser humano encontra-se em permanente mutação, em contínua construção. A ciência experimental, em cada forma que apresenta para demonstrar as coisas do mundo, mostra nova face do conhecimento. A razão, nesta linha de entendimento, apresenta sempre níveis diferentes de respostas. Outras correntes do Empirismo teorizam que todo conhecimento funda-se na experiência, sem exceção. O Empirismo parece ter surgido na Inglaterra. Entre outros filósofos que aparecem como empiristas, destacamos: Thomas Op. cit., 1588-1679, John Locke
} 1632-1704.” (SILVA, 2010, p. 179. Nota de rodapé n. 646). 


\section{FUNDAMENTOS DA SUSTENTABILIDADE}

A categoria Sustentabilidade comporta ser estudada em vários sentidos: Cultural, Social, Político, Jurídico, Econômico e Ambiental. Em razão disso se faz necessário estabelecer um acordo semântico quanto ao sentido da referida categoria. Neste estudo utilizase da ideia de Sustentabilidade, a partir de uma perspectiva transdisciplinar ${ }^{26}$. Desse modo, Sustentabilidade assemelha-se a categorias como Justiça e Dignidade, nas quais os conteúdos renovam-se, sob o ângulo da Hermenêutica, no decorrer do tempo, do espaço e do Ser humano.

O adjetivo sustentabilidade era utilizado apenas por algumas comunidades científicas para descrever a possibilidade de um ecossistema não perder a sua capacidade de adaptar-se ou [in]evolução após uma adversidade ${ }^{27}$. De acordo com Sérgio Aquino (2013), a categoria Sustentabilidade "representa um novo valor centrado na Responsabilidade e permite a compreensão da transição de outro paradigma de manutenção da vida na Terra que não esteja fundamentado, exclusivamente, no crescimento econômico".

Estabelecem-se oito critérios (ou estratégias) dialogais e complementares, nos quais a Sustentabilidade precisa atuar para se evitar a aceleração da extinção humana do planeta, quais sejam: a) social; b) ambiental; c) cultural; d) ecológico; e) econômico; f) territorial; g) político (nacional); h) político (internacional) ${ }^{28}$.

A temática Sustentabilidade ${ }^{29}$ ganhou destaque a partir de 1983, quando a médica Gro Harlem Brudtland, ex-Primeira Ministra da Noruega, presidiu a Comissão Mundial sobre o Meio Ambiente e Desenvolvimento da Organização das Nações Unidades - ONU e em

26 Essa perspectiva transdisciplinar é sugerida por Henrique Leff apud Bodnar. Parafraseando Leff, Bodnar entende essa perspectiva Transdisciplinar como: Deve ser entendido como estratégia de produção cognitiva baseada no intercâmbio dos saberes, de técnicas de abordagem e dialéticas de problematização que resultam na produção de novos objetos. Não é apenas uma abordagem inter ou multidis ciplinar, modo comum de investigar determinado objeto ou campo de problematização, pois na transdiciplinariedade o que é determinante é a possibilidade da criação do novo, de um conhecimento que vai além, ultrapassa as possibilidades de abordagem de um campo do saber, exatamente como decorrência da fusão dialética e criativa dos conhecimentos. Henrique Leff, embora nomine equivocadamente de interdisciplinar o que é na verdade transdisciplinar, apresenta um exemplo extraordinário de conhecimento produzido por intermédio de uma abordagem transdiciplinar: trata -se de reconstrução de um objteto da biologia (estrutura e funções da matéria viva - DNA), com a participação de conhecimentos diversos da área biológica e com os da genética formal (citologia, microbiologia e bioquímica) (LEFF, 2006, p. 70 In BODNAR, 2014).

27 "Capacidade de um ecossistema absorver tensões ambientais sem, perceptivelmente, mudar seu estado ecológico para um estado diferente. Conceito oriundo da física: propriedade de alguns materiais de, quando exigidos ou submetidos a estresse, acumular energia sem que ocorra ruptura. Atualmente, o termo também é utilizado para caracterizar pessoas que são capazes de lidar com problemas sob pressão ou estresse." (VEIGA, 2010. p. 11).

28 A composição dessa categoria refere-se a três obras: VEIGA, 2010, p. 39/40; SACHS, 2009, p. 85-87; FERRER, 2012.

${ }^{29}$ Para aprofundar a temática relacionada ao Desenvolvimento Sustentável e Sustentabilidade, recomenda -se a leitura do artigo de BODNAR, 2014. 
1987, quando apresentou à comunidade internacional o relatório de sua comissão, denominado de "Nosso futuro comum", que traz o conceito de "desenvolvimento sustentável" para o discurso público. Esse relatório apresenta o conceito operacional de desenvolvimento sustentável como "[...] o desenvolvimento que encontra as necessidades atuais sem comprometer a habilidade das futuras gerações de atender suas próprias necessidades." Prossegue alertando para o problema da desigualdade social como um elemento que contribui para a crise ecológica: 'Um mundo onde a pobreza e a desigualdade são endêmicas estará sempre propenso a crises ecológicas, entre outras [...]”. E consigna que em relação ao desenvolvimento sustentável as sociedades devem estar atentas "[...] às necessidades humanas tanto pelo aumento do potencial produtivo como pela garantia de oportunidades iguais para todos". O relatório, já em 1987 indicava que "Muitos de nós vivemos além dos recursos ecológicos, por exemplo, em nossos padrões de consumo de energia... No mínimo, o desenvolvimento sustentável não deve pôr em risco os sistemas naturais que sustentam a vida na Terra: a atmosfera, as águas, os solos e os seres vivos" (ONU, 2014). Essas recomendações proporcionaram a realização da Conferência das Nações Unidas sobre o Meio Ambiente e o Desenvolvimento, realizada no Rio de Janeiro, em 1992. Na Conferência adotou-se a "Agenda 21" para a proteção do nosso planeta e seu desenvolvimento sustentável. Os governos, através da Agenda 21, delinearam um programa detalhado para a ação, a fim de afastar o mundo do atual modelo insustentável de crescimento econômico, direcionando-o para atividades que protejam e renovem os recursos ambientais, do qual o crescimento e o desenvolvimento dependem. As áreas de ação incluem: proteger a atmosfera; combater o desmatamento, a perda de solo e a desertificação; prevenir a poluição da água e do ar; deter a destruição das populações de peixes e promover uma gestão segura dos resíduos tóxicos. Além das questões ambientais para abordar os padrões de desenvolvimento que causam danos ao meio ambiente, a Agenda incluiu: a pobreza e a dívida externa dos países em desenvolvimento; padrões insustentáveis de produção e consumo; pressões demográficas e a estrutura da economia internacional e ainda, recomendou meios de fortalecer o papel desempenhado pelos grandes grupos - mulheres, organizações sindicais, agricultores, crianças e jovens, povos indígenas, comunidade científica, autoridades locais, empresas, indústrias e ONGs - para alcançar o desenvolvimento sustentável (ONU, 2014).

Porém, somente a partir de 2002 é que passa ser adequado utilizar-se a categoria Sustentabilidade, ao invés de Desenvolvimento Sustentável. A partir desse ano consolida-se a ideia de que nenhum dos elementos - ecológico, social e econômico - deve ser hierarquicamente superior ou compreendido como variável de segunda categoria. "Todos são 
complementares, dependentes e só quando implementados sinergicamente é que poderão garantir um futuro mais promissor” (BODNAR, 2014).

Desse modo, temos a Sustentabilidade como o "[...] desenvolvimento que satisfaz as necessidades do presente, sem comprometer a capacidade das gerações vindouras satisfazerem as suas próprias necessidades" (ONU,2014).

E com esse papel de satisfazer as necessidades do presente, sem comprometer a capacidade das gerações futuras temos no Brasil a presença das Microempresas - ME e das Empresas de Pequeno Porte - EPP (BRASIL, 2014).

De acordo com estudos realizados pelo Serviço Brasileiro de Apoio às Microempresas e Empresas de Pequeno Porte-SEBRAE, o Brasil tem aproximadamente seis milhões de ME e EPP. Desse modo, encontra-se no topo da lista de países mais empreendedores do mundo. Esse volume de ME e EPP corresponde a 97\% de todas as empresas existentes o país, sendo apenas 3\% do total formado por empresas médias e grandes (MINISTÉRIO DO DESENVOLVIMENTO, INDÚSTRIA E COMÉRCIO EXTERIOR, 2014).

As ME e EPP movimentam a economia nacional e como tal merecem nossa atenção e foco. Elas empregam aproximadamente $52 \%$ de todos os trabalhadores urbanos do país e geram 20\% do Produto Interno Bruto - PIB brasileiro.

Sua importância, presença e força transformadora são inquestionáveis. Quando se aborda a temática da sustentabilidade, deve-se entendê-la nas suas dimensões ambiental, social, econômica e tecnológica. Desse modo, não há como não se pensar nas ações e reflexos das MEs e EPPs, mesmo que se esteja diante de uma classificação para efeitos contábeis, de direito tributário e empresarial aplicado à empresa.

\section{FUNDAMENTOS DO PRINCÍPIO DA SEGURANÇA JURÍDICA}

A categoria Segurança Jurídica assume a figura de Princípio da ordem jurídica estatal, de acordo com Luiz Marinoni (2014) e de Direito Fundamental, conforme Ingo Sarlet $^{30}$. A Constituição da República Federativa do Brasil - CRFB/88 refere-se à segurança

\footnotetext{
30 Ingo Sarlet relaciona segurança jurídica à noção de dignidade da pessoa humana e como tal trata -se de um princípio fundamental: "Considerando que também a segurança jurídica coincide com uma das mais profundas as pirações do ser humano, viabilizando, mediante a garantia de uma certa estabilidade das relações jurídicas e da própria ordem jurídica como tal, tanto a elaboração de projetos de vida, bem como a sua realização, des de logo é perceptível o quanto a ideia de segurança jurídica encontra-se umbilicalmente vinculada à própria noção de dignidade da pessoa humana. (...) a dignidade não restará suficientemente respeitada e protegida em todo o lug ar onde as pessoas estejam sendo atingidas por um tal nível de instabilidade jurídica que não estejam mais em condições de, com um mínimo de segurança e tranquilidade, confiar nas instituições sociais e estatais (incluindo o Direito) e numa certa estabilidade das suas próprias posições jurídicas” (SARLET, 2006, p. 11).
} 
como valor fundamental, arrolando-a no caput do artigo $5^{\circ}$ como direito inviolável, ao lado dos direitos à vida, liberdade, iguald ade e propriedade.

Ainda que não se refira expressamente a um direito fundamental à segurança jurídica, a CRFB/88 possui inúmeros dispositivos que a tutelam, como os incisos II (princípio da legalidade), XXXVI (inviolabilidade do direito adquirido, da coisa julgada e do ato jurídico perfeito), XXXIX (princípio da legalidade e anterioridade em matéria penal) e XL (irretroatividade da lei penal desfavorável) do artigo $5^{\circ}$. O Estado brasileiro, além de ter o dever de tutelar a segurança jurídica, deve realizar as suas funções de modo a prestigiá-la, estando proibido de praticar atos que a violem (MARINONI, 2014).

O Princípio da Segurança Jurídica estabelece que o Poder Público, em suas relações administrativas, ou judiciais, respeite e cumpra as situações de fato e de direito já consolidadas, e as preserve perante lei nova, em proveito da estabilidade e paz nas relações jurídicas.

Celso Antônio Bandeira de Mello (2001), ao descrever o Princípio da Segurança Jurídica, que, na sua visão, se não for o mais importante dentre todos os princípios gerais de Direito é, indiscutivelmente, um dos mais importantes, parece afirmar que o Direito deve ensejar certa estabilidade, um mínimo de certeza na regência da vida social. Exemplifica com os institutos da prescrição, da decadência, da preclusão (na esfera processual), da usucapião, da irretroatividade da lei, do direito adquirido, como expressões concretas que bem revelam esta profunda busca à estabilidade, à segurança, conatural do Direito.

J. J. Gomes Canotilho (1991) considera o Princípio da Segurança Jurídica como um dos elementos constitutivos do Estado de Direito. A Segurança Jurídica é um valor, estado ideal de coisas que aponta para a previsibilidade, determinando certeza nas relações. Mas não basta garantir a mera certeza da aplicação da lei. É preciso garantir também a igualdade nesta aplicação.

\section{FUNDAMENTOS DO ATIVISMO JUDICIAL}

A categoria Ativismo Judicial [Judicial Activism] surgiu em discussões realizadas nos Estados Unidos da América do Norte. Atribui-se o surgimento da expressão a um artigo publicado em 1947, na revista Fortune. O autor da expressão, em seu texto, analisava a atuação da Suprema Corte daquele país em relação ao controle de constitucionalidade das leis do New Deal do Presidente Roosevelt. Segundo ele, havia dois grupos de juízes: os ativistas e os que apregoavam a autocontenção judicial (SOLIANO, 2014). 
A categoria Judicial Activism, segundo pesquisas de Vitor Soliano (2014), surge sem preocupações científicas e, desde então, passou a designar uma determinada forma de atuação judicial.

Elival da Silva Ramos (2010, p. 129) propõe o conceito operacional de ativismo judicial como:

[...] o exercício da função jurisdicional para além dos limites impostos pelo próprio ordenamento que incumbe, institucionalmente, ao Poder Judiciário fazer atuar, resolvendo litígios de feições subjetivas (conflitos de interesse) e controvérs ias jurídicas de natureza objetiva (conflito normativo). Há, como visto, uma sinalização claramente negativa no tocante às práticas ativistas, por importarem na desnaturação da atividade típica do Poder Judiciário, em detrimento dos demais Poderes.

O case estadunidense - Marbury v. Madison - inaugurou o ativismo judicial. O juiz John Marshall afirma nesse julgamento a possibilidade de controle de constitucionalidade das leis, mesmo que não previsto no texto constitucional de seu país. Em 1824, e em referência ao caso Osbom v. Bank of the United States, destaca-se que o Poder Judiciário nunca poderia ser exercido com o propósito de dar efetividade à vontade do magistrado, mas sempre com a finalidade de realizar a vontade da lei, em manifestação clara de repúdio às consequenciais do ativismo (GUEDES, 2013).

A atuação ativista do Judiciário brasileiro é apresentada como uma solução para os problemas sociais. Para o ministro do Supremo Tribunal Federal - STF, Luís Roberto Barroso (2011, p. 279-280), o ativismo nada mais é do que "uma participação mais ampla e intensa do Judiciário na concretização dos valores e fins constitucionais, com maior interferência no espaço de atuação dos outros dois poderes”.

O sistema atual de controle de constitucionalidade brasileiro favorece o Ativismo Judicial, como ressalta Carlos Reverbel (2014, p. 9) "se em todo o sistema Europeu a competência para declarar a inconstitucionalidade de uma lei é restrita a uma única Corte Suprema [...] no Brasil, todos os juízes e tribunais são capazes de declarar a inconstitucionalidade de uma lei’'.

Sobre a problemática oriunda do Ativismo Judicial, Vinícius Estefaneli Ramos (2014, p. 83) destaca que "o ativismo na busca de uma solução mágica, na extração de um princípio que fundamente a decisão, acaba por afrontar a separação de poderes e, faz do juiz um verdadeiro legislador e inclusive contrariando o Estado de Direito, em que impera a lei”'.

No Brasil, Lenio Streck (2011) destaca-se como um dos importantes críticos do Ativismo Judicial. Argumenta que o Ativismo Judicial ocorre quando um juiz ou tribunal 
decide a partir de argumentos de moral, vontade política, enfim, quando o direito é substituído pelas convicções e desejos individuais de cada magistrado.

De modo sintético, Lenio Streck (2012, p. 110) combate o Ativismo, o Positivismo Fático, alertando o Operador do Direito ${ }^{31}$ para dizer do "compromisso com a Constituição e com a legislação democraticamente construída, no interior da qual há uma discussão no plano da esfera pública, das questões ético-morais da sociedade".

O Ativismo Judicial aparece como um problema "que torna a interferência judicial, nos moldes de um ativismo judicial à brasileira, perigosa, porque está vinculada a um ato de vontade do legislador (TASSINARI, 2013, p. 108). Por meio do Ativismo Judicial, o judiciário assume uma atuação de total interferência política, e com a concessão de "superpoderes" aos magistrados, culmina no comprometimento da democracia brasileira.

O Ativismo está baseado em um ato não condicionado por pressupostos jurídicos, mas sim pela mera vontade do magistrado, apresentando-se, portanto, como um forte problema, podendo acarretar inclusive na perda de autonomia do Direito, uma vez que na atual conjuntura, há indiscutivelmente uma tendência de delegar à jurisdição a concretização de direitos (TASSINARI, 2013).

Pode-se entender o Ativismo Judicial como uma interferência excessiva do Poder Judiciário em áreas tradicionalmente de responsabilidade dos demais Poderes do Estado (representativos), razão pela qual se discute a infração a teoria da separação dos poderes nesta temática. O Brasil acompanha o constitucionalismo moderno descrito por J.J. Canotilho (2011, p.52), ao adotar a separação dos poderes $^{32}$, para romper em definitivo com o

\footnotetext{
31 Para lógica deste estudo, adere-se ao conceito operacional proposto para "Operador do Direito", formulado por Garcia e Aquino: "A expressão designa todo bacharel em Direito com conhecimento sobre a técnica legislativa no intuito de compreendê-la, interpretá-la, aplicá-la e cumpri-la, a fim de oferecer ordem e segurança jurídica aos Cidadãos. O vocábulo "Operador" denota trabalho mecânico. A diferença (ou passagem) entre o Operador do Direito e o Jurista, portanto, é o seu auto-aperfeiçoamento pautado pela Educação nos diversos campos do conhecimento humano. A ação mecânica cede espaço à compreens ão, podendo -se dialogar (ou transitar) entre os $s$ aberes a fim de se estabelecer o Direito como fenômeno compreens ivo a partir das múltiplas inter-retroações humanas." (GARCIA, 2013).

32 Adere-se às observações formuladas por Carolina Scherer Bicca, em artigo de sua autoria publicado em 2011, o qual destaca que a teoria original da separação dos poderes, formulada por Montesquieu em sua clás sica obra "O espírito das leis", encontra-s e, na atualidade, bem modificado. Como não se trata do cerne deste estudo, farse-á uma rápida explanação nesta nota de rodapé sobre a proposta original de Montesquieu, a qual não é esta descrita em nossa Constituição de 1988. Seu modelo tem como pano de fundo a experiência política inglesa de estruturação de poderes do Estado, capaz de prevenir o absolutismo, por meio de um mecanismo institucional onde "o poder freie o poder" (le pouvoir arrête le pouvoir), pois todo homem que tem poder é tentado a abusar dele. Serve-se do estudo da Carolina Scherer Bicca para sintetizar o pensamento teorizado por Montesquieu, no qual os poderes tinham a seguinte configuração: 1) poder legislativo, em que o príncipe ou magistrado faz, corrige ou revoga leis; 2) poder executivo das coisas que dependem do direito das gentes, em que se faz a paz ou a guerra, envia ou recebe embaixadas, estabelece a segurança, previne invasões; e 3) poder executivo das cois as que dependem do direito civil, em que se pune os crimes ou julga as querelas dos indivíduos, sendo estes dois últimos denominados por Montesquieu, respectivamente, como poder executivo do Estado e poder de julgar.
} 
constitucionalismo antigo, representado pelos abusos políticos do mundo da Antiguidade Clássica, principalmente dentre os gregos e os romanos.

Neste contexto a tradicional cláusula dos "poderes independentes e harmônicos" da CRFB/88 passa a não mais ter ênfase no adjetivo "independentes", o que ressaltaria na adoção do Ativismo Judicial - uma supervalorização do Poder Judiciário. A ênfase deve estar no adjetivo "harmônicos", no qual sobressai a função de cada um dos três poderes, segundo depreende-se da lição de J.J. Canotilho (2010, p. 187).

\section{FUNDAMENTOS DA POLÍTICA JURÍDICA}

O novo Direito a ser construído pela Política Jurídica há que se comunicar com a Axiologia, a Antropologia, a Ética, a Política, a Sociologia, sob a égide de um humanismo, entendido como a teoria que focaliza o Ser humano no centro de irradiação e atenção dos valores criados pela sociedade (SILVA, 2010).

A Política Jurídica 'tem sua preocupação básica não com o direito vigente, mas com o direito desejado" (MELO, 1994, p. 14). Frente a essa dimensão do Direito produzido na atualidade, Osvaldo Ferreira de Melo (1994) propõe alguns questionamentos reflexivos: Como deve ser o Direito? Fruto retórico da dominação ou instrumento estratégico das mudanças? Deverá ser ele descompromissado com a degradação do meio ambiente, mantendo-se como ineficaz remédio para os delitos contra a natureza ou como poderoso mecanismo da prevenção desses males? O Direito deve ter compromisso apenas com o presente ou deverá estar empenhado na construção ética do devir?

Em razão de tais questionamentos, meramente exemplificativos, pode-se afirmar que a Política Jurídica teorizada por Osvaldo Ferreira de Melo é o meio adequado para contribuir não só para a elaboração de um conjunto normativo, mas de toda a construção de um Direito, que deve ser capaz de propiciar o desenvolvimento de uma sociedade mais equilibrada, mais sustentável, mais justa, diferenciando-se aqui da Dogmática Jurídica que trata do Direito vigente, na interpretação e na aplicação do Direito.

\footnotetext{
Segundo Montesquieu, citado por "tudo estaria perdido se o mesmo homem ou o mesmo corpo dos principais, ou dos nobres, ou do povo, exercesse esses três poderes". Assim, o principal objetivo de Montesquieu era receitar uma estrutura de poderes que prevenisse contra o absolutismo, razão pela qual obteve como resultado a prescrição de um mecanis mo institucional onde "o poder freie o poder". Para Montesquieu o governo ideal era o governo moderado, face à necessidade de que os três poderes não fossem exercidos pelo mesmo homem, devendo ser constituído pela Monarquia - governo de um ordenado para o bem comum - pela Aristocracia governo dos melhores, ou dos nobres - ordenado para o bem comum - e Democracia - governo do povo ordenado para o bem comum. (BICCA, 2014). Como se pode perceber, a Constituição da Republica Federativa do Brasil de 1988 já não adota a concepção original de Montesquieu, razão pela qual não há dúvida de estarmos diante de um constitucionalis mo moderno, o qual trabalha com poderes "harmônicos" entre si.
} 
Deve-se "desconcentrar os olhos das fontes tradicionais do Direito e atentar para o vulcanismo existente na sociedade, para os movimentos sociais com suas pautas de reivindicações" (MELO, 1994, p. 17). O Operador do Direito não necessita usurpar de atribuições e/ou funções dos outros poderes, principalmente do legislativo, para encontrar e apresentar uma resposta adequada às questões jurídicas relacionadas à Sustentabilidade. A Política Jurídica assegura o Princípio da Segurança Jurídica e se mostra atenta aos valores presentes na sociedade. Existindo norma não amparada no sistema, outra deve ser proposta, atuando a Política Jurídica nesta correção. De acordo com Osvaldo Ferreira de Melo "Será o caso de afastar do sistema essa norma indesejada socialmente e propor, com o apoio do conhecimento político-jurídico, a norma adequada" (MELO, 1994, p. 17).

De modo sintético, Sérgio Aquino (2014) propõe o conceito operacional de Política Jurídica teorizada por Osvaldo Ferreira de Melo (1998, p. 80), ao qual se adere e conclui-se essa temática. "Trata-se da produção e aplicação do Direito a partir das proposições éticas e culturais de um determinado Povo sob o ângulo de sua época." Sérgio Aquino prossegue ainda destacando que "Não se trata de uma preocupação exclusiva com o Direito que pode vir a ser (devir), mas, também, com o vigente (o Direito que é). [...] pois, a partir da escolha dos valores de uma Sociedade, cria-se, a partir da Utopia, a Norma Jurídica justa e socialmente útil. "

\section{CONSIDERAÇÕES FINAIS}

Para que o Poder Judiciário, por meio de suas decisões judiciais monocráticas ou colegiadas, consiga, cada vez mais, apresentar uma solução eficaz e satisfatória aos problemas que the são submetidos, especialmente no que diz respeito aos temas relacionados à Sustentabilidade, há necessidade de estabelecer-se um novo paradigma para o Direito. Esse novo paradigma resulta da conexão teórica entre a Razão e a Sensibilidade = Razão Sensível. O Direito elaborado na Pós-modernidade deve espelhar, enquanto expressão cultural, também a Sensibilidade, abandonando-se a primazia da Razão como a única forma do conhecimento humano e o fundamento do Direito.

O Operador do Direito despreza o fato do Direito ser fruto da cultura humana e não de inspiração divina ou produção mecanicista ou cibernética. Vivemos uma realidade Pósmoderna, que exige ações pautadas na Sustentabilidade e que assegurem o Princípio da Segurança Jurídica. 
É necessário compreender que o império da Razão não se mostra mais apto a perceber e apreender a experiência vivida. A Razão não percebe a realidade humana, com suas alegrias e tristezas, dor e prazer, amor e ódio, ordem e desordem, vida e morte.

A união da Razão e da Sensibilidade possibilita ao Operador do Direito, encontrar uma solução para os conflitos, em harmonia com o Direito justo, com o Direito desejável. Se assim proceder, o Magistrado e/ou o Operador do Direito não estará se afastando dos Princípios gerais do Direito - que são o reflexo da inspiração permanente e universal do Direito -, nem do Direito normativo que tanto alguns defendem e zelam sob o argumento da defesa da "Segurança Jurídica".

É com essa reflexão que se pretende apresentar uma proposta solução ao problema formulado no início deste estudo - o Direito que temos não está resolvendo os problemas submetidos ao Poder Judiciário. Apesar de obter-se uma decisão judicial, os problemas não se resolvem de forma satisfatória e efetiva. A solução está na utilização da Razão Sensível e da Política Jurídica, por permitirem que se corrija o Direito vigente e a construção daquele que pode vir a ter em sentido humanitário.

Precisamos ser mais "pró-ativos" na construção e aplicação do Direito Pós-moderno, mas isso não significa defender o Ativismo Judicial. Fazer como se fazia há dez, quinze ou vinte anos atrás não é sinônimo de "segurança jurídica", mas sim de total descompasso com os novos tempos!

Para a manutenção de um Estado Democrático de Direito, especialmente após a Constituição da República Federativa do Brasil de 1988, tem-se claro que o Ativismo Judicial não se mostra como a alternativa mais adequada para produção e aplicação do Direito na Pósmodernidade. A adoção do Ativismo provocará no Brasil a insegurança jurídica. Demandas complexas, pautadas por interesses econômicos, defesa da aristocracia, intolerância, ou egoísmo decorrente da Sustentabilidade não terão uma resposta adequada se não por meio de decisões e/ou ações pautadas pela Política Jurídica, teorizada por Osvaldo Ferreira de Melo.

O paradigma que se busca na Pós-modernidade é a conexão da Razão lógica à Razão Instrumental e/ou à Razão Sensível. O fato da Modernidade ter classificado a realidade e o Ser humano, não são motivos para nos mantermos inertes, desconexos. Precisamos "realizar o Direito”. As transformações são lentas, mas ocorrem. Isso é importante e necessário. Cabe a nós, Seres humanos pós-modernos, esse papel transformador. Se é o Ser humano quem produz o Direito e a sua produção e aplicação passa por um processo hermenêutico, façamos a nossa parte! 


\section{REFERÊNCIAS}

ABBAGNANO, Nicola. Dicionário de filosofia. Tradução de Alfredo Bosi. 2. ed. São Paulo: Martins Fontes, 1998.

AGOSTINHO, Santo. A cidade de Deus: (contra os pagãos). Tradução de Oscar Paes Leme. Bragança Paulista: Universitária São Franscisco, 2003. v. 2. Parte I.

AGOSTINHO, Santo. A cidade de Deus: (contra os pagãos). Tradução de Oscar Paes Leme.

4. ed. Petrópolis: Vozes, São Paulo: Federação Agostiniana Brasileira, 2001. Parte II.

AGOSTINHO, Santo. Confissões. Tradução de J. Oliveira Santos e A. Ambrósio de Pina. 9. ed. Petrópolis: Vozes, 1988.

AQUINO, Sérgio Ricardo Fernandes de. Rumo à Cidadania Sul-americana : reflexões sobre a sua viabilidade no contexto da UNASUL a partir da Ética, Fraternidade e Sustentabilidade. 2013. 338 f.; Tese (doutorado em Ciência Jurídica) - Universidade do Vale do Itajaí, Itajaí, 2013. Disponível em: <http:/Siaibib01.univali.br/pdf/Sergio Ricardo Fernandes de Aquino2013.pdf>. Acesso em: 5 mai. 2014.

BARROSO, Luís Roberto. Judicialização, ativismo judicial e legitimidade democrática. Rio de Janeiro: Lumen Juris, 2011.

BÍBLIA SAGRADA: Nova tradução na linguagem de hoje. Barueri: Sociedade Bîblica do Brasil, 2000. 628 p. (Antigo Testamento).

BICCA, Carolina Scherer. A busca pela essência da separação de poderes em Montesquieu no controle judicial das políticas públicas. Revista Eletrônica Direito e Política. Programa de Pós-Graduação Stricto Sensu em Ciência Jurídica da UNIVALI, Itajaí, v.6, n.3, $3^{\circ}$ quadrimestre de 2011. Disponível em: www.univali.br/direitoepolitica - ISSN 1980-7791. Acesso em: 2 mai. 2014.

BODNAR, Zenildo. A sustentabilidade por meio do direito e da jurisdição. Revista Jurídica Cesumar-Mestrado. V. 11, n. 1., p. 325-343, já./jun. 2011. Disponível em: < file://C :/Users/Usuario/Downloads/1885-6867-1-PB.pdf>. Acesso em: 19 mai. 2014.

BOFF, Leonardo. Ethos mundial: um consenso mínimo entre os humanos. Brasilia: Letraviva, 2000.

BRASIL. Lei Complementar 123, de 14 de dezembro de 2006. Institui o Estatuto Nacional da Microempresa e da Empresa de Pequeno Porte; altera dispositivos das Leis n. 8.212 e 8.213, ambas de 24 de julho de 1991, da Consolidação das Leis do Trabalho - CLT, aprovada pelo Decreto-Lei n. 5.452 , de $1^{\circ}$ de maio de 1943, da Lei n. 10.189, de 14 de fevereiro de 2001, da Lei Complementar n. 63, de 11 de janeiro de 1990; e revoga as Leis n. 9.317, de 5 de dezembro de 1996, e 9.841, de 5 de outubro de 1999. Disponível em: <http://www.planalto.gov.br/ccivil_03/Leis/LCP/Lcp123.htm> Acesso em: 19 mai. 2014.

CANOTILHO, J. J. Gomes. Direito constitucional. Coimbra: Almedina, 1991. 
CANOTILHO, J. J. Gomes. Direito constitucional e teoria da constituição. 7. ed. Coimbra: Almedina, 2011.

CANOTILHO, J. J. Gomes (Coord.) et al. Direitos fundamentais sociais. São Paulo: Saraiva, 2010.

CASSIRER, Ernst. Ensaio sobre o homem: introdução a uma filosofia da cultura humana. Tradução de Tomás Rosa Bueno. São Paulo: Martins Fontes, 2005.

DIAS, Maria da Graça dos Santos; MELO, Osvaldo Ferreira de; SILVA, Moacyr Motta da. Política jurídica e pós-modernidade. Florianópolis: Conceito Editorial, 2009.

DUSSEL, Enrique. Ética da libertação: na idade da globalização e da exclusão. Tradução de Ephraim Ferreira Alves, Jaime A. Clasen e Lúcia M. E. Orth. 2. ed. Petrópolis: Vozes, 2002.

FERREIRA, Aurélio Buarque de Holanda. Novo dicionário da língua portuguesa. 2. ed. rev. e aum. Rio de Janeiro: Nova Fronteira. 1986.

FERRER, Gabriel Real. "Calidad de vida, médio ambiente, sostenibilidad y ciudadanía ¿construímos juntos el futuro?" Novos Estudos Jurídicos, v. 17, n. 3, p. 319, Dez. 2012. ISSN 2175-0491. Disponível em: <http://siaiweb06.univali.br/seer/index.php/nej/artic le/view/4202>. Acesso em: 19 mai. 2014.

GARCIA, Marcos Leite; AQUINO, Sérgio R. F. Direitos Fundamentais líquidos em terrae brasilis: reflexões. Sequência (UFSC), v. 62, jul/2011. p. 223-260, Doi:10.5007/2177- 7055.2011. Disponível em: $<$ http://periodicos.ufsc.br/index.php/sequencia/article/view/21777055.2011v32n62p223/18621> Acesso em: 2 abr. 2013.

GUEDES, Néviton. O juiz entre o ativismo judicial e a autocontenção. Revista Consultor Jurídico ConJur. 23 jul. 2012. Disponível em: http:/www.conjur.com.br/2012-jul23/constituicao-poder-juiz-entre-ativismo-judicial-autocontencao. Acesso em: 18 nov. 2013. LONGO, Adão. O direito de ser humano. Rio de Janeiro: Forense Universitária, 2004.

LYOTARD, Jean-François. A condição pós-moderna. 9. ed. Rio de Janeiro: José Olympio, 2006.

MAFFESOLI, Michel. Elogio da razão sensível. Tradução de Albert Christophe Migueis Stuckenbruck. Petrópolis: Vozes, 1998.

MARINONI, Luiz Guilherme. Os precedentes na dimensão da segurança jurídica. Páginas de Direito. Disponível em: < http://www.tex.pro.br/home/artigos/261-artigos- mar-2014/6443os- precedentes-na-dimensao-da-seguranca-juridica > Acesso em: 3 mai. 2014.

MELO, Osvaldo Ferreira de. Dicionário de política jurídica. Florianópolis: OAB-SC Ed., 2000.

MELO, Osvaldo Ferreira de. Ética e Direito. Jus Navigandi, Teresina, ano 10, n. 812, 23 set. 2005. Disponível em: <http://jus.com.br/artigos/7324>. Acesso em: 3 mai. 2014. 
MELO, Osvaldo Ferreira de. Fundamentos da política jurídica. Porto Alegre: Sérgio Antonio Fabris Editor/CPGC-UFSC. 1994.

MELO, Osvaldo Ferreira de. Temas atuais de política do direito. Porto Alegre: Sergio Antonio Fabris Editor/CMCJ-UNIVALI, 1998.

MELLO, Celso Antônio Bandeira de. Curso de direito administrativo. 13. ed. São Paulo: Malheiros, 2001.

MINISTÉRIO DO DESENVOLVIMENTO, INDÚSTRIA E COMÉRCIO EXTERIOR. Secretaria de Comércio e Serviços. MINISTÉRIO DA JUSTIÇA. Secretaria de Reforma do Judiciário. INSTITUTO RECUPERA BRASIL - IRB. Guia de Recuperação Judicial aplicado as ME e EPP. Disponível em: < http://www.mdic.gov.br/arquivos/dwnl_1323289760.pdf> Acesso em: 19 mai. 2014.

NEDEL, José. Ética aplicada: pontos e contrapontos. São Leopoldo: Unisinos, 2004. ONU. Organização das Nações Unidas no Brasil. A ONU em ação. Disponível em: <http://www.onu.org.br/a-onu-em-acao/a-onu-e-o-meio-ambiente/>. Acesso em: 5 mai. 2014.

ONU. Organização das Nações Unidas. Nosso futuro comum. p. 24, ponto 27. Disponível em: <http///www.onu.org.br/rio20/img/2012/01/N8718467.pdf>. Acesso em: 5 mai. 2014.

PASOLD, Cesar Luiz. Metodologia da pesquisa jurídica: teoria e prática. 12. ed. revista. Florianópolis: Conceito. 2011.

RAMOS, Elival da Silva. Ativismojudicial: parâmetros dogmáticos. São Paulo: Saraiva, 2010.

RAMOS, Vinícius Estefaneli. Teoria dos precedentes judiciais e sua eficácia no sistema brasileiro atual. Jus Navigandi, Teresina, ano 18, n. 3621, 31 mai. 2013. Disponível em: <http:/jus.com.br/artigos/24569>. Acesso em: 3 mai. 2014.

REALE, Miguel. Filosofia do direito. 20. ed. São Paulo: Saraiva, 2002.

REALE, Miguel. Lições preliminares de direito. 13. ed. São Paulo: Saraiva, 1986.

REALE, Miguel. O direito como experiência: introdução à epistemologia jurídica. 2. ed. São Paulo: Saraiva, 1992.

REALE, Miguel. Teoria tridimensional do direito. 5. ed., rev. e reestruturada, 7. tiragem. 2005. São Paulo: Saraiva, 1994.

REVERBEL, Carlos Eduardo Dieder. Ativismo Judicial e Estado de Direito. Revista Eletrônica do Curso de Direito da UFSM (março de 2009). v. 4, n. 1. Disponível em: $<$ http://cascavel. ufs m. br/revis tas/ojs-

2.2.2/index.php/revistadireito/article/view/7028/4246\#.UvbAZGJdX_E>. Acesso em: 3 mai. 2014. p. 9. 
SACHS, Ignacy. Caminhos para o desenvolvimento sustentável. Rio de Janeiro: Garamond, 2009.

SARLET, Ingo Wolfgang. A eficácia do direito fundamental à segurança jurídica: dignidade da pessoa humana, direitos fundamentais e proibição de retrocesso social no direito constitucional brasileiro. Revista de Direito Constitucional e Internacional, v. 57. out./dez./2006. São Paulo: Revista dos Tribunais.

SILVA, Moacyr Motta da. Direito, justiça, virtude moral e razão: reflexões. 3. ed. Curitiba: Juruá, 2010.

SOLIANO, Vitor. Ativismo judicial no Brasil: uma definição. Revista Eletrônica Direito e Política. Programa de Pós-Graduação Stricto Sensu em Ciência Jurídica da UNIVALI, Itajaí, v. 8, n.1, $1^{\circ}$ quadrimestre de 2013. Disponível em: www.univali.br/direitoepolitica ISSN 1980-7791. Acesso em: 2 mai. 2014.

STRECK, Lenio Luiz. O que é isto - decido conforme minha consciência? 3. ed. Porto Alegre: Livraria do Advogado, 2012.

STRECK, Lenio Luiz. Verdade e consenso: constituição, hermenêutica e teorias discursivas. 4. ed. São Paulo: Saraiva, 2011.

TASSINARI, Clarissa. Jurisdição e ativismo judicial: limites da atuação do judiciário. Porto Alegre: Livraria do Advogado, 2013.

VEIGA, José Eli da. Sustentabilidade: a legitimação de um novo valor. 2. ed. São Paulo: SENAC, 2010. 